ENCYCLOPEDDIE Encyclopédie berbère

BERBERE

$34 \mid 2012$

34| Nemencha - Nybgenii

\title{
Nigritae / Nigrites
}

Jehan Desanges

\section{OpenEdition}

Journals

Édition électronique

URL : https://journals.openedition.org/encyclopedieberbere/2742

DOI : $10.4000 /$ encyclopedieberbere. 2742

ISSN : 2262-7197

\section{Éditeur}

Peeters Publishers

\section{Édition imprimée}

Date de publication : 5 octobre 2012

Pagination : 5554-5555

ISBN : 978-90-429-2718-6

ISSN : 1015-7344

\section{Référence électronique}

Jehan Desanges, « Nigritae / Nigrites », Encyclopédie berbère [En ligne], 34 | 2012, document N58a, mis en ligne le 15 décembre 2020, consulté le 28 juin 2022. URL : http://journals.openedition.org/ encyclopedieberbere/2742; DOI : https://doi.org/10.4000/encyclopedieberbere.2742

Ce document a été généré automatiquement le 17 février 2022.

(c) Tous droits réservés 


\title{
Nigritae / Nigrites
}

\author{
Jehan Desanges
}

1 Strabon (XVII, 3, 3, C826) relate que, selon des récits auxquels il n'accorde pas de crédit, peut-être le Périple d'Ophélas, Nigritae et Pharousii*, situés, dit-on, à trente jours de marche de Lynx (Larache ou Tanger, souvent confondus), auraient détruit trois cents établissement tyriens sur les golfes qui suivent (en s'éloignant vers le sud ou le sud-est) le golfe Emporique, lequel s'étend, d'après ses indications, au sud de Lynx. La moindre des étrangetés de cette tradition n'est pas que les comptoirs tyriens soient localisés en dehors du golfe «Emporique ", alors que cet adjectif le désigne précisément comme le golfe «des Comptoirs»! La situation des Nigritae à trente jours de marche de Lynx, qu'il s'agisse de Larache ou de Tanger, soit environ $900 \mathrm{~km}$, les rejette loin des limites de la future province de Tingitane. Sans doute venaient-ils, comme les Pharousii, avec lesquels ils sont souvent mentionnés, des confins de l'Éthiopie, s'ils n'étaient euxmêmes Éthiopiens. Strabon, citant en un autre passage (I, 2, 26, C33) Éphore, nous informe que, selon les habitants du Tartessos, les Éthiopiens auraient envahi la Libye jusqu'en son extrémité occidentale et occupé une grande partie d'un littoral qui, dans le contexte, ne peut être que le littoral atlantique. La mention des habitants du Tartessos permet de supposer que cette tradition s'était répandue à partir de Gades (Cadix). On peut penser qu'elle n'est pas sans rapport avec celle qui mettait en cause Nigritae et Pharousii. Strabon (XVII, 3, 7, C828) mentionne une seconde fois les Nigritae,

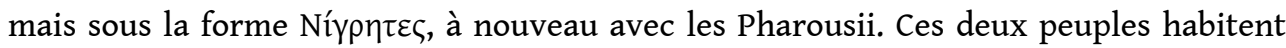
au-dessus, c'est-à-dire au sud, des Maurousii*, près des Éthiopiens Hesperii* (occidentaux), sont équipés d'un arc, comme les Éthiopiens, et utilisent des chars à faux. La situation des Nigritae et des Pharousii comme des populations intermédiaires entre les Éthiopiens au sud, et les Gétules au nord, est confirmée par Strabon dans un tableau ethnographique general des peuples de la Libye qui provient de Poseidonios (Str. II, 5, 33, C131), ainsi que par Méla (I, 22). Ce dernier, en un second passage (III, 104), campe les Nigritae près des Gétules : ce sont des nomades qui fréquentent le littoral atlantique là où l'on exploite pourpre et murex (îlots de Mogador?).

2 Pline l'Ancien $(\mathrm{V}, 43)$ classe au contraire Nigritae et Pharusii parmi les Ethiopiens. Il ajoute, dans une syntaxe quelque peu équivoque (éd. Desanges : 452), que les Nigritae tiennent leur nom du fleuve Nigris qu'il a déjà nommé $(\mathrm{en} \mathrm{V}, 30)$ et sur lequel il va 
revenir $(\mathrm{V}, 44)$, ce que confirme, très clairement cette fois, Stéphane de Byzance (Ethn.,

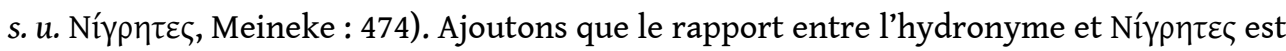
encore prouvé par Ptolémée (G. IV, 6, 4, Müller : 741), puisque celui-ci nomme le grand marais forme par le fleuve Nigeir, Nigritis (cf., en parallèle, le rapport entre l'hydronyme $\mathrm{Ge}(i) r / G i r / G i r i s$ et les Girrei/Girrhaei*). Contrairement à Méla, Pline $(\mathrm{V}, 43)$ fait des Nigritae un peuple de l'intérieur des terres, à l'opposé des Perorsi* qui touchent à l'océan. Ptolémée (IV, 6, 5:743) fait état des Nigritae parmi les peuples majeurs de Libye intérieure. Il les situe au nord du Nigeir et à l'est des Daradae* qui sont établis à l'embouchure du fleuve homonyme (oued Dra*).

La mention du fleuve Nigris par Pline n'est pas d'un grand secours pour localiser les Nigritae. En effet, le Nigris qu'il signale en $\mathrm{V}, 30$, semble situé en une toute autre région que celle qu'il mentionne en V, 44, et indirectement en V, 43 (cf. encore VIII, 77 : le fons Nigris, chez les Éthiopiens Hesperii, qui serait aussi l'origine du Nil, et V, 52 : Nigrum [acc.], mais Solin, 32, 5 : Nigrim. En tout état de cause, il ne doit pas s'agir d'une « source noire»). Selon toute vraisemblance, le flumen Nigris de V, 30, qui sert d'horizon administratif à la province d'Afrique, correspond plutôt au Гríp de Ptolémée (IV, 6, 4 : $739 ; 5: 743 ; 12: 752)$ et au Giris de la Table de Peutinger « que certains appellent Nil » (segm. VII, 2, et VIII, 1 ; sur Giris comme autre nom du Nil, cf. Pline, V, 53). En revanche le Nigris relativement proche de l'Atlantique $(\mathrm{V}, 44)$ correspond au Níyzip de Ptolémée (IV, 6, 4:741; $5: 743 ; 8: 749$ ), et peut-être, pour partie, au fleuve Ger rencontré par Suétonius Paulinus lors de sa campagne dans l'actuel Atlas marocain (Pline, V, 15 ; une fraction du haut Nil venu de l'Atlas s'appelle Agger, selon Vitruve, VIII, 2, 6; le Ravennate, passim, nomme Ger le Giris de la Table de Peutinger). Il ne faut pas s'étonner de ces flottements. D'une part, les tenants de l'origine occidentale du Nil imaginaient un ensemble de pertes et de résurgences dans le désert qui permettait de relier idéalement au Nil, en un seul système, un certain nombre d'oueds sahariens indépendants les uns des autres jusqu'en Maurétanie océanique ; d'autre part, les hydronymes Ge(i)r, Gir ou Giris, Nige(i)r ou Nigris semblent reposer sur la même base libyco-berbère (cf. la notice suivante, N58b de S. Chaker).

\section{INDEX}

Mots-clés : Antiquité, Maroc, Onomastique, Sahara, Tribu 